\title{
Optimum Medium for Lipase Production by Lipolytic Filamentous Fungi Isolated from Kendari Landfill Soil
}

\author{
Nur Rayani ${ }^{1}$ and Miftahul IImi ${ }^{1, *}$ \\ ${ }^{1}$ Laboratory of Microbiology, Faculty of Biology, Universitas Gadjah Mada, J. Teknika Selatan, Sekip Utara, Yogyakarta 55281, Indonesia \\ ${ }^{*}$ Corresponding author: m.ilmi@ugm.ac.id
}

KEYWORDS
Lipase
Optimization
Aspergillus
Taguchi
Response surface
methodology (RSM)
SUBMITTED 1 October 2020
REVISED 8 April 2021
ACCEPTED 14 April 2021

ABSTRACT Lipase produced by Aspergillus is widely known and used in many industrial sectors. In a previous study, three lipolytic filamentous fungi were isolated from Kendari (Southeast Sulawesi, Indonesia) landfill soil and identified as Aspergillus niger KE1, Aspergillus terreus KC1, and Aspergillus fumigatus KE6. However, the optimization of these isolates has not been reported. In this study, statistical optimization was selected because it is more effective, efficient, economical, and robust in achieving results, and the possibility of analyzing the interaction effects among factors. Three lipolytic isolates were screened in the initial medium to obtain the highest lipolytic isolate, which was used in the medium optimization process. Optimization was performed using the series experimental design of Taguchi and RSM. Optimization successfully obtained the optimum medium with the reduction of the medium component from the previously reported medium. Aspergillus niger KE1 was the selected isolate with the highest lipase productivity after $72 \mathrm{~h}$ in the initial medium. The significant factors affecting lipase production were peptone, olive oil, glucose, and $\mathrm{MgSO}_{4} \cdot 7 \mathrm{H}_{2} \mathrm{O}$. The model equation obtained was $Y=1043-228 A+300 B-19803 C+99 A^{\star} A+5720 B^{*} B+292855 C^{*} C-979 A^{*} B+6563 A^{*} C$ - $56338 B^{*} C$. This model successfully predicted the lipase productivity with an $R^{2}$ of $96.9 \%$. The optimized medium was composed of $2 \%$ peptone, $0.1 \%$ olive oil, $0.5 \%$ glucose, and $0.075 \% \mathrm{MgSO}_{4} .7 \mathrm{H}_{2} \mathrm{O}$. Using the medium, lipase productivity increases 4.7 -fold. Our results suggest that $A$. niger KE1 is a potential lipase source which catalyses the esterification reaction. Further research is needed to purify and characterize the lipase enzyme of this isolate.

(c) The Author(s) 2021. This article is distributed under a Creative Commons Attribution-ShareAlike 4.0 International license.

\section{INTRODUCTION}

Lipases (triacylglycerol hydrolase EC 3.1.1.3) catalyse the hydrolysis of triglycerides into fatty acids and glycerol. The enzyme also catalyses the synthesis of esters through transesterification, which is important in biodiesel production (Chen et al. 2011). The most widely applied lipases are produced from microorganisms due to their thermal stability, $\mathrm{pH}$ stability, substrate specificity, and activity in organic solvents (Hasan et al. 2009; Costa and Peralta 1999). Filamentous fungi are considered as a potential source of lipase (Falony et al. 2006; Dutra et al. 2008; Thakur 2012). Some advantages of using the filamentous fungi as extracellular lipase producers are their capability to utilize agricultural waste products as a source of nutrients, their ability to produce lipase in solid or broth media, and the simpler separation method of fungal mycelium from the produced enzyme (Sharma et al. 2016).

Aspergillus has been known as the lipase producer that is suitable to be used in many industrial sectors. A previous study by Yanti et al. (2019) obtained three lipolytic filamentous fungi from this genus, namely Aspergillus niger KE1, Aspergillus terreus KC1, and Aspergillus fumigatus KE6, isolated from Kendari landfill soil. These filamentous fungi were the selected lipolytic isolates according to qualitative screening using the rhodamine B agar method. However, the ability of these isolates in producing lipase quantitatively and their optimization is unknown.

Most extracellular lipase production is determined by the composition of the production medium, which is essential to supply nutrients for the microorganisms. Hence, medium composition is selected as a parameter in the optimization process. Furthermore, in the optimization process, the more factors used the greater the number of experiments needed. Therefore, a statistical method is needed to design these experimental processes. Taguchi and response surface methodology (RSM) are two statistical methods that are widely used to replace the conventional approach, such as one factor at a time (Subramonian et al. 2014). Taguchi is used to find the significant factor affecting experimental response(s), while RSM is used to optimize, to find the interaction between the significant factor, and to build the equation model for predicting the optimum response. Some studies have looked at the optimization of lipase production statistically, such as the optimization of the growth condition using FFD and RSM designs (Malilas et al. 2013), and the optimization of an oil source using the RSM design (Oliveira et al. 2017), but there are few reports concerning the medium optimization of lipase production by lipolytic filamentous fungi, statistically, using the series experimental design of Taguchi and RSM. In the present work, the screening of the highest lipase-producing lipoly- 
tic filamentous fungi was firstly performed, some significant factors were selected using the Taguchi design, and these significant factors were further optimized using the RSM design.

\section{MATERIALS AND METHODS}

\subsection{Materials}

\subsubsection{Microbial growth medium}

Olive oil was obtained from a local market (Yogyakarta, Indonesia). Potato dextrose agar (HiMedia), peptone (Oxoid), glucose (Merck), $\mathrm{KCl}$ (JT Beaker), $\mathrm{K}_{2} \mathrm{HPO}_{4}$ (JT Beaker), and $\mathrm{MgSO}_{4} \cdot 7 \mathrm{H}_{2} \mathrm{O}(\mathrm{BDH})$ were purchased at analytical grade from chemical suppliers in Indonesia.

\subsubsection{Chemicals for lipase assay}

Ethanol (Merck), oleic acid (Merck), isooctane (Merck), pyridine (Merck), and copper (II) acetate monohydrate (Merck) were purchased at analytical grade from chemical suppliers in Indonesia.

\subsubsection{Microorganism and culture condition}

Three lipolytic filamentous fungi isolated from Kendari landfill soil in Southeast Sulawesi, Indonesia: A. niger KE1, A. terreus KC1, and A. fumigatus KE6. These isolates were provided by the Laboratory of Microbiology, Universitas Halu Oleo, Indonesia. Pure isolates were kept in potato dextrose agar medium (PDA).

\subsection{Methods}

\subsubsection{Screening of the highest lipase-producing filamentous fungi}

Screening was carried out by growing isolates in the lipase production initial medium based on a previous study (Adham and Ahmed 2009). The medium contained 3\% (w/v) peptone, $0.05 \%(\mathrm{w} / \mathrm{v}) \mathrm{MgSO}_{4}, 0.05 \%(\mathrm{w} / \mathrm{v}) \mathrm{KCl}, 0.2 \%(\mathrm{w} / \mathrm{v})$ $\mathrm{K}_{2} \mathrm{HPO}_{4}, 0.5 \%$ (v/v) olive oil, and $0.5 \%(\mathrm{w} / \mathrm{v})$ glucose were placed in $250 \mathrm{~mL}$ Erlenmeyer flasks. The flasks were inoculated with spore suspension containing 106 spore/ml from a 5-day-old culture grown on PDA and incubated at $30^{\circ} \mathrm{C}$ with $100 \mathrm{rpm}$ agitation. The culture was harvested every 24 $\mathrm{h}$ for $120 \mathrm{~h}$ to determine the best time of lipase production of each isolate. All experiments were performed in triplicate. One selected isolate with the highest lipase productivity would be used in the medium optimization process.

\subsubsection{Experimental design for medium optimization.}

Screening of significant factors using Taguchi design. An L27 orthogonal array was used to determine which factors were significant for lipase production. The factors and their levels are shown in Table 1. The experiment was performed in $250 \mathrm{~mL}$ shake flasks with $50 \mathrm{~mL}$ medium and incubated at $30^{\circ} \mathrm{C}$ in a shaker $(100 \mathrm{rpm})$ for $72 \mathrm{~h}$. Lipase productivity was measured after $72 \mathrm{~h}$. All experiments were performed in triplicate.

Optimization of significant factors using Box-Behnken design. The significant factors were optimized using RSM. A BoxBehnken design with three factors and three levels was used for fitting a second-order response surface. The experiment was performed in $250 \mathrm{~mL}$ shake flasks with $50 \mathrm{ml}$ medium and incubated at $30^{\circ} \mathrm{C}$ in a shaker $(100 \mathrm{rpm})$ for 72 h. Lipase productivity was measured after $72 \mathrm{~h}$. All experiments were performed in triplicate.

Validation and productivity profile. The optimum predicted productivity was obtained using a response optimizer in RSM. Validation was performed by repeating the experiment using the optimum medium solution. Spore suspension of the selected isolate was inoculated in this medium and was incubated at $30^{\circ} \mathrm{C}$ at $100 \mathrm{rpm}$ for $72 \mathrm{~h}$. Lipase productivity was measured after $72 \mathrm{~h}$. After that, the productivity profile was determined by growing the selected isolate in the initial medium and optimized medium. Each medium was incubated at $30^{\circ} \mathrm{C}$ at $100 \mathrm{rpm}$ for $168 \mathrm{~h}$, and was harvested after 12, 24, 36, 48, 72, 96, 120, 140, and $168 \mathrm{~h}$ of incubation. All experiments were performed in triplicate.

\subsubsection{Lipase assay and productivity measurement}

The filamentous fungi biomass was harvested from $50 \mathrm{~mL}$ medium by paper filtration method and dried in an oven at $70^{\circ} \mathrm{C}$ for $24 \mathrm{~h}$. The weight of the biomass was measured in grams. The extracellular lipase was estimated according to the lipase activity in the supernatant. Lipase activity was determined by incubating $100 \mu \mathrm{L}$ filtrate with $1 \mathrm{~mL}$ isooctane containing $0.25 \mathrm{M}$ oleic acid and $0.25 \mathrm{M}$ ethanol for 20 $\min$ at $30^{\circ} \mathrm{C}$. The amount of oleic acid at $0 \mathrm{~min}$ and after 20 min was determined using the cupric-acetate pyridine colorimetric assay (Kwon and Rhee 1986). One unit of activity $(\mathrm{U})$ is defined as the amount of oleic acid $(\mu \mathrm{mol} / \mathrm{mL})$ converted to product per minute. Lipase productivity $(\mathrm{U} / \mathrm{g})$ is the ratio of lipase activity $(\mathrm{U} / \mathrm{mL})$ and biomass $(\mathrm{g} / \mathrm{mL})$.

\subsubsection{Data analysis}

All data were analyzed statistically at $p<0.05$ using SPSS Version 16 and Minitab Version 17. SPSS was used to perform the analysis of variance, while Minitab was used to analyze the experimental results of the Taguchi design, build the polynomial equation, and predict the optimal parameters of the Box-Behnken design.

\section{RESULTS}

\subsection{Screening of the highest lipase-producing filamentous fungi}

Screening of the highest lipase-producing isolate was done quantitatively using the submerged fermentation method. The spore suspension of each isolate was inoculated in the initial medium and was incubated at $30^{\circ} \mathrm{C}$ with $100 \mathrm{rpm}$ agitation for $120 \mathrm{~h}$. Lipase productivity was measured every $24 \mathrm{~h}$. The lipase productivity of the three lipolytic filamentous fungi is shown in Figure 1. Aspergillus niger KE1 had the highest lipase productivity after $72 \mathrm{~h}$ incubation

TABLE 1. Factors and levels used in Taguchi design.

\begin{tabular}{lccc}
\hline Factors & Level 1 & Level 2 & Level 3 \\
\hline Peptone (\%) & 1.5 & 3.0 & 4.5 \\
$\mathrm{MgSO}_{4} .7 \mathrm{H}_{2} \mathrm{O}(\%)$ & 0.0 & 0.05 & 0.1 \\
$\mathrm{KCl}(\%)$ & 0.0 & 0.05 & 0.1 \\
$\mathrm{~K}_{2} \mathrm{HPO}_{4}(\%)$ & 0.0 & 0.2 & 0.4 \\
Olive oil (\%) & 0.25 & 0.5 & 0.75 \\
Glucose (\%) & 0.0 & 0.5 & 1.0 \\
\hline
\end{tabular}




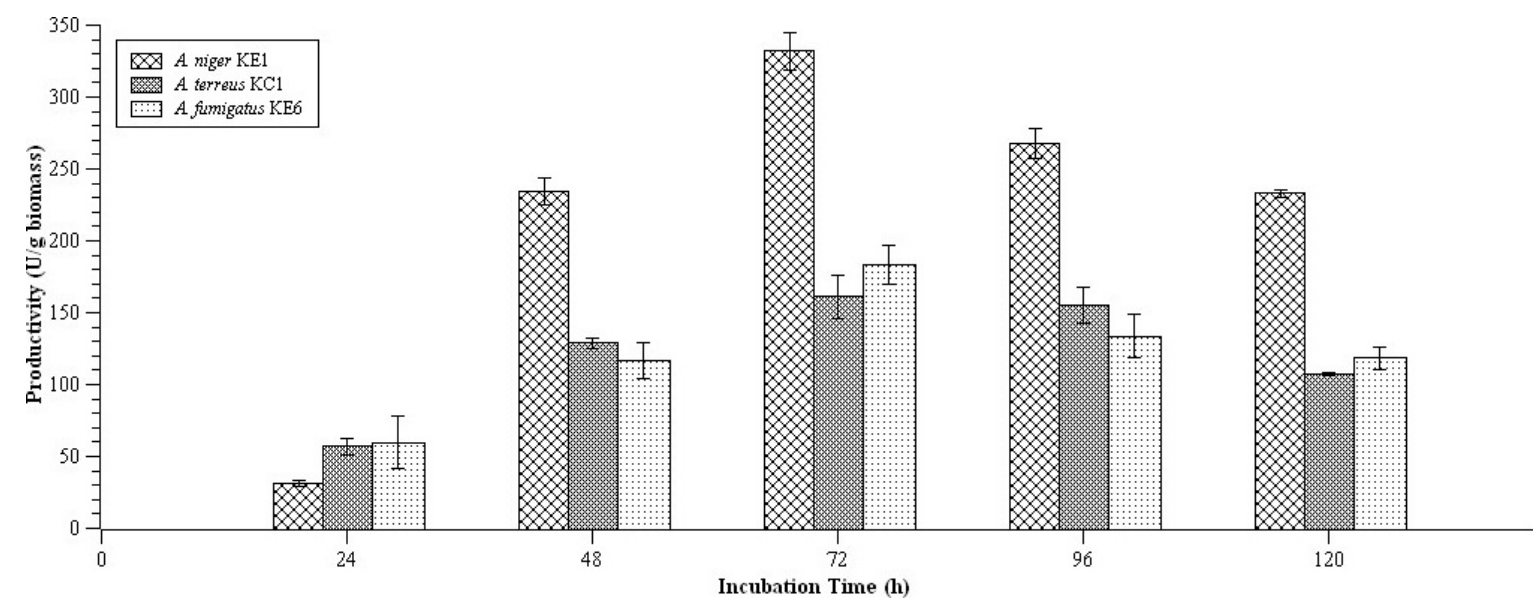

FIGURE 1. Lipase productivity of three lipolytic isolates in initial medium. Incubation was carried out at $30^{\circ} \mathrm{C}$ with $100 \mathrm{rpm}$ agitation for $120 \mathrm{~h}$.

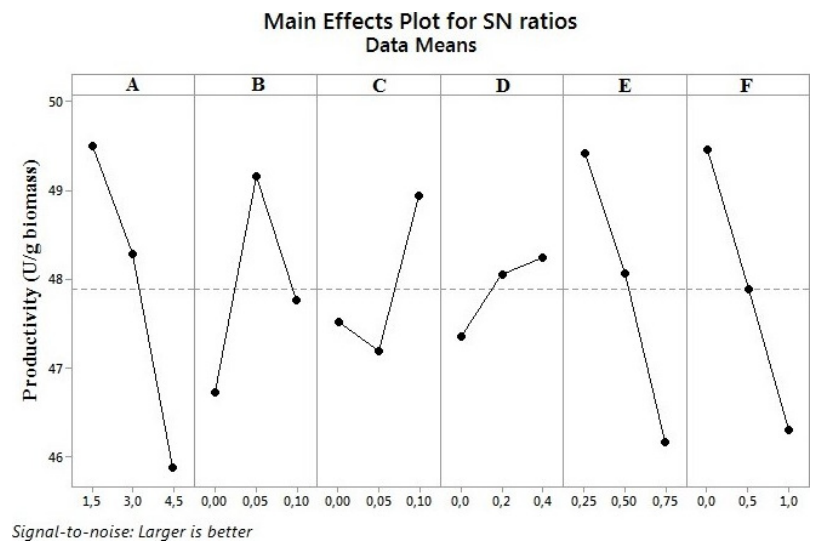

FIGURE 2. Main effects plot for $\mathrm{S} / \mathrm{N}$ ratio of lipase productivity; (A) peptone, (B) $\mathrm{MgSO}_{4} .7 \mathrm{H}_{2} \mathrm{O}$, (C) $\mathrm{KCl}$, (D) $\mathrm{K}_{2} \mathrm{HPO}_{4}$, (E) olive oil, and (F) glucose.

(331.95 $\pm 12.76 \mathrm{U} / \mathrm{g}$ biomass). Thus, this isolate was used in the medium optimization process.

\subsection{Screening of significant factors using Taguchi design}

Screening of significant factors was carried out by growing A. niger KE1 in various experimental designs of Taguchi. The spore suspension of this isolate was inoculated in each medium and was incubated at $30^{\circ} \mathrm{C}$ with $100 \mathrm{rpm}$ agitation for $72 \mathrm{~h}$. Lipase productivity was measured after 72 hours of incubation. The result of Taguchi analysis is shown as the main effect plot for the $\mathrm{S} / \mathrm{N}$ ratio of lipase productivity in Figure 2. Analysis of variance (ANOVA) showed that peptone, olive oil, glucose, $\mathrm{MgSO}_{4} \cdot 7 \mathrm{H}_{2} \mathrm{O}$, and the interaction factors of olive oil and glucose were significant with a $p$ value $<0.05$ (Table 2). All of these these factors can be used in a further optimization process.

\subsection{Optimization of significant factors using Box-Behnken design}

Optimization of significant factors was done by growing A. niger KE1 in various experimental designs of Box-Behnken in RSM. The spore suspension of this isolate was inoculated in each medium and was incubated at $30^{\circ} \mathrm{C}$ with $100 \mathrm{rpm}$ agitation for $72 \mathrm{~h}$. Lipase productivity was measured after 72 $\mathrm{h}$ of incubation. The responses (productivity) for each experiment along with the predicted responses are listed in Table 3. Response surface regression was employed to fit the polynomial equation to the experimental data(Equation
TABLE 2. ANOVA analysis of each factor using Taguchi design.

\begin{tabular}{lccccc}
\hline Factors & DF & \multicolumn{1}{c}{ SS } & MS & F-value & $P$-value \\
\hline Peptone & 2 & 60.798 & 30.399 & 10.13 & 0.004 \\
$\mathrm{~K}_{2} \mathrm{HPO}_{4}$ & 2 & 26.598 & 13.299 & 4.43 & 0.042 \\
$\mathrm{KCl}$ & 2 & 15.460 & 7.730 & 2.57 & 0.125 \\
$\mathrm{~K}_{2} \mathrm{HPO}_{4}$ & 2 & 3.867 & 1.933 & 0.64 & 0.546 \\
Olive oil & 2 & 47.997 & 23.998 & 7.99 & 0.008 \\
Glucose & 2 & 45.000 & 22.500 & 7.49 & 0.010 \\
Olive oil*Glucose & 4 & 44.114 & 11.029 & 3.67 & 0.043 \\
Error & 10 & 30.022 & 3.002 & & \\
Total & 26 & 273.855 & & & \\
\hline
\end{tabular}

Note: $\mathrm{DF}=$ degrees of freedom, $\mathrm{SS}=$ sum of squares, $\mathrm{MS}=$ mean square $\mathrm{R}^{2}=0.89$, adjusted $\mathrm{R}^{2}=0.715$.

1). The results of the analysis of variance (ANOVA) are summarized in Table 4. The ANOVA showed that the model had a low $p$ value $(p<0.05)$, indicating that the obtained model was significant. The values of coefficient of determination $\left(\mathrm{R}^{2}\right)$ was calculated to be 0.969 and showed no lack of fit for the model, so this polynomial equation was reliable and can be used to predict the lipase productivity. The $p$ values of each factor and their interactions were also checked. As shown in Table 4 , three linear coefficients of A, B, and C ( $p<$ $0.05)$, tow quadratic coefficients of $B^{2}$ and $C^{2}(p<0.05)$, and the interaction factors of $\mathrm{B}$ and $\mathrm{C}(p<0.05)$ were significant to the lipase productivity. Generally, the experimental productivity and predicted productivity were similar according to the distribution of the experimental points near to the trendline of the predicted productivity (Figure 3, data from triplicate).

$$
\begin{aligned}
Y & =1043-228 A+300 B-19803 C+99 A^{*} A+5720 B^{*} B \\
& +292855 C^{*} C-979 A^{*} B+6563 A^{*} C-56338 B^{*} C
\end{aligned}
$$

where $Y$ is lipase productivity ( $\mathrm{U} / \mathrm{g}$ biomass), $A$ is peptone (\%), $B$ is olive oil+glucose (\%), and $C$ is $\mathrm{MgSO}_{4} \cdot 7 \mathrm{H}_{2} \mathrm{O}$.

\subsection{Validation and productivity profile}

Validation was performed by repeating the experiment using the optimum medium condition. Spore suspension of the selected isolate was inoculated in this medium and was 
TABLE 3. Experiment design with experimental and predicted values of productivity.

\begin{tabular}{|c|c|c|c|c|c|}
\hline \multirow[t]{2}{*}{ Runs } & \multicolumn{3}{|c|}{ Factors } & \multicolumn{2}{|c|}{ Productivity (U/g biomass) } \\
\hline & $A(\%)$ & B (\%) & $C(\%)$ & Experimental & Predicted \\
\hline 1 & 1 & $0.1: 0.5$ & 0.05 & 726.21 & 724.77 \\
\hline 2 & 2 & $0.1: 0.5$ & 0.05 & 930.32 & 978.41 \\
\hline 3 & 1 & $0.4: 0.5$ & 0.05 & 558.66 & 516.35 \\
\hline 4 & 2 & $0.4: 0.5$ & 0.05 & 469.15 & 475.79 \\
\hline 5 & 1 & $0.25: 0.5$ & 0.025 & 557.29 & 610.04 \\
\hline 6 & 2 & $0.25: 0.5$ & 0.025 & 637.65 & 567.30 \\
\hline 7 & 1 & $0.25: 0.5$ & 0.075 & 649.12 & 763.59 \\
\hline 8 & 2 & $0.25: 0.5$ & 0.075 & 1033.41 & 1019.40 \\
\hline 9 & 1.5 & $0.1: 0.5$ & 0.025 & 645.07 & 656.41 \\
\hline 10 & 1.5 & $0.4: 0.5$ & 0.025 & 721.58 & 678.20 \\
\hline 11 & 1.5 & $0.1: 0.5$ & 0.075 & 1251.55 & 1336.55 \\
\hline 12 & 1.5 & $0.4: 0.5$ & 0.075 & 708.39 & 603.72 \\
\hline 13 & 1.5 & $0.25: 0.5$ & 0.05 & 539.89 & 522.98 \\
\hline 14 & 1.5 & $0.25: 0.5$ & 0.05 & 592.60 & 522.98 \\
\hline 15 & 1.5 & $0.25: 0.5$ & 0.05 & 482.22 & 522.98 \\
\hline
\end{tabular}

Note: $\mathrm{A}=$ peptone, $\mathrm{B}=$ olive oil+glucose, $\mathrm{C}=\mathrm{MgSO}_{4} \cdot 7 \mathrm{H}_{2} \mathrm{O}$.

incubated at $30^{\circ} \mathrm{C}$ with $100 \mathrm{rpm}$ agitation for $72 \mathrm{~h}$. Both the experimental and predicted optimum medium condition and optimum productivity are given in Table 5 . The experimental value obtained was $1570.34 \mathrm{U} / \mathrm{g}$ biomass (mean of triplicate), which was very close to the predicted value of $1595.98 \mathrm{U} / \mathrm{g}$ biomass, thus the validation was successful, and the equation was adequate to describe lipase productivity by response surface methodology.

The productivity profile was determined by growing the selected isolate in the initial and optimized media. Each medium was incubated at $30^{\circ} \mathrm{C}$ at $100 \mathrm{rpm}$ and harvested after $12,24,36,48,72,96,120,140$, and $168 \mathrm{~h}$ of incubation. The lipase productivity profile of A. niger KE1 in both initial and optimized media is shown in Figure 4. The optimum lipase productivity was obtained at $72 \mathrm{~h}$. After optimization, it increased 4.7-fold (373\%) from the initial medium, as $331,95 \pm 12,76 \mathrm{U} / \mathrm{g}$ biomass to $1570.34 \pm 22.48 \mathrm{U} / \mathrm{g}$ biomass.

\section{DISCUSSION}

\subsection{Aspergillus niger KE1 as selected lipase-producing fungi}

Aspergillus niger has been known as one of the potential lipase-producing filamentous fungi. Many studies reported that this species has great lipase activity, both using the submerged fermentation method and solid-state fermentation with the addition of olive oil theas carbon source and inducer (Thakur 2012; Cihangir and Sarikaya 2004; Sharma et al. 2001). In lipase production, incubation time pla anys important role (Ayinla et al. 2017)

As shown in Figure 1, the production of lipase increased steadily and reached its maximum productivity after $72 \mathrm{~h}$ by A. niger KE1. Lipase productivity gradually decreased as the incubation time increased further. This result substantiated the work of Mukhtar et al. (2015), which showed a similar pattern of this lipase productivity. Lipase productivity at the initial incubation time was low due to adaptation of the fungus to the new medium. Fungal spores need time for germination and to form hypha. Further incubation time
TABLE 4. ANOVA analysis for response surface quadratic model.

\begin{tabular}{lcrrrr}
\hline Factors & $\begin{array}{c}\text { Degrees of } \\
\text { freedom }\end{array}$ & $\begin{array}{r}\text { Sum of } \\
\text { squares }\end{array}$ & $\begin{array}{c}\text { Mean } \\
\text { squares }\end{array}$ & F-value & $P$-value \\
\hline Model & 9 & 810060 & 90007 & 17.44 & 0.003 \\
A & 1 & 45521 & 45521 & 8.82 & 0.031 \\
B & 1 & 227650 & 227650 & 44.10 & 0.001 \\
C & 1 & 137364 & 137364 & 26.61 & 0.004 \\
AA & 1 & 2241 & 2241 & 0.43 & 0.539 \\
BB & 1 & 61162 & 61162 & 11.85 & 0.018 \\
CC & 1 & 123699 & 123699 & 23.96 & 0.004 \\
AB & 1 & 21553 & 21553 & 4.18 & 0.096 \\
AC & 1 & 26917 & 26917 & 5.21 & 0.071 \\
BC & 1 & 178534 & 178534 & 34.59 & 0.002 \\
Lack of Fit & 3 & 18644 & 6215 & 1.73 & 0.386 \\
Error & 2 & 7165 & 3583 & & \\
Total & 14 & 835869 & & & \\
\hline
\end{tabular}

Note: $R^{2}=0.969$, adjusted $R^{2}=0.913, A=$ peptone, $B=$ olive oil+glucose, $C$ $=\mathrm{MgSO}_{4} \cdot 7 \mathrm{H}_{2} \mathrm{O}$.

would decrease the metabolic activity due to the depletion of nutrients or accumulation of metabolic toxins, hence the productivity also decreases (Imandi et al. 2010). In addition, Ayinla et al. (2017) stated that a decrease in lipase production may likely be due to the proteases secreted by the fungus, which can cleave and inactivate lipase.

\subsection{Significant factors in lipase production from A. niger KE1}

As shown in Figure 2 and Table 2, peptone, $\mathrm{MgSO}_{4} \cdot 7 \mathrm{H}_{2} \mathrm{O}$, olive oil, and glucose were the significant factors for the lipase productivity of A. niger KE1. Those factors have their own important roles in lipase production. Bora and Bora (2012) stated that the release of NH4+ ions from peptone will stimulate the growth and then can increase the enzyme yield. Other reports also stated that peptone was the best organic nitrogen source for lipase production in Fusarium verticillioides, A. carbonarius IMI 366159, and Trichoderma citrinoviride (Facchini et al. 2015; Ire and Ike 2014; Akyl and Cihangir 2018).

$\mathrm{MgSO}_{4} \cdot 7 \mathrm{H}_{2} \mathrm{O}$ provides magnesium and sulphur sources. This mineral salt is needed to maintain the osmotic balance and provide the appropriate cationic environment. Magnesium can stabilize the ribosome structure, nucleic acid, enzyme activation in hydrolysis, and phosphate transport, while the reduction of sulphate is used to form cysteine (Hughes and Poole 1989; Griffin 1981).

Many studies have also reported that lipase production increased and gave optimum productivity with the addition of olive oil. Besides serving as a carbon source, olive oil is used as an inducer for lipase production in some fungi, such as Rhizopus homothallicus, A. niger AC-5, A. awamori, A. terreus, and (Rodriguez et al. 2006; Brooks and Asamudo 2011; Xia et al. 2011; Iftikhar et al. 2012; Mahmoud et al. 2015). Although the utilization of olive oil as a carbon source can increase lipase production, many studies also found that some filamentous fungi need the addition of glucose in the medium to maximize their lipase production. Glucose is considered to be important in supporting hypha growth, especially as a component of cell wall building blocks.

Some fungi need the mixture of glucose and olive oil as a carbon source to maximize lipase production; for ex- 


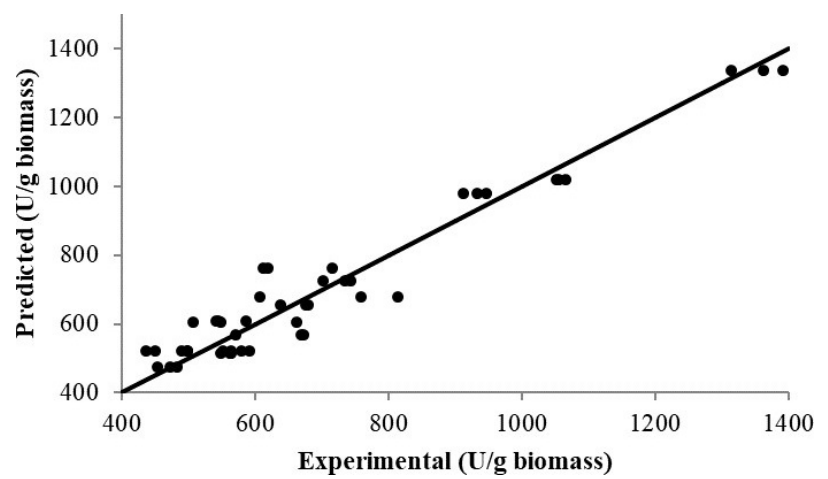

FIGURE 3. Parity plot of experimental and predicted of lipase productivity.

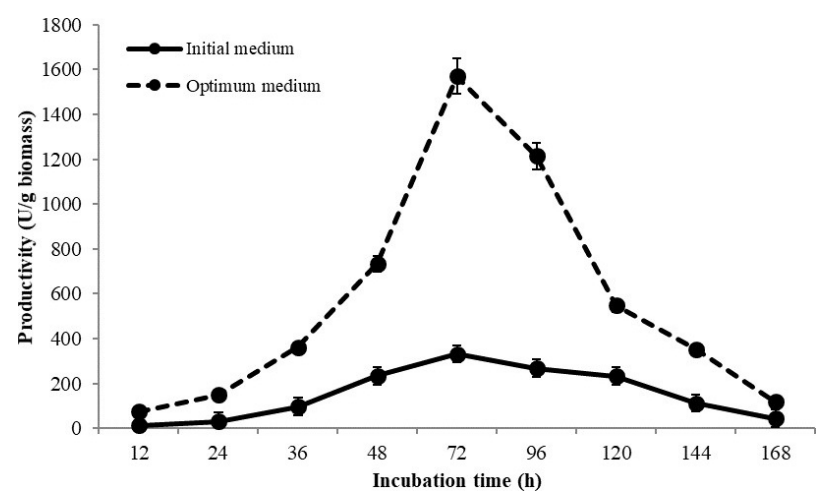

FIGURE 4. Lipase productivity obtained using initial and optimum media. Incubation was performed at $30^{\circ} \mathrm{C}$ with $100 \mathrm{rpm}$ for $168 \mathrm{~h}$.

ample, Mucor racemosus needs the mixture of glucose and olive oil at a concentration of $0.5 \%: 5 \%$, respectively (Nadia et al. 2010). Other research has reported that lipase production increased up to $36 \%$ in A. niger MTCC2594 when using the mixture of two carbon sources from groundnut oil cake and wheat bran (1:3) (Mala et al. 2007). Although glucose was significant at its low level, its interaction with olive oil was significant at concentrations of 0.5 and $0.25 \%$, respectively (data not shown). Hence, glucose was still used in the optimization process.

The other factors, $\mathrm{KCl}$ and $\mathrm{K}_{2} \mathrm{HPO}_{4}$, were not significant. Some studies also reported that these factors were not significant in lipase production (Awad et al. 2015; Teng and $\mathrm{Xu}$ 2008). According to the screening result obtained, four significant factors were selected to be used in the optimization process, while the rest was reduced or not used in the next optimization process.

\subsection{Optimization of significant factors}

After obtaining the significant factors, these factors were further optimized in RSM, especially using the BoxBehnken design. The polynomial equation (Equation 1) was suitable to describe the actual condition according to the results of ANOVA (Table 4). The equation had a significant value $(p<0.05)$. This value described that the model inaccuracy was less than $5 \%$. The equation also had no lack of fit ( $p$ $>0.05$ ), which showed that the estimated response surface could represent the actual condition. Furthermore, the model also had a high coefficient determinant $(\mathrm{R}$-squared $=$ 96.9\%), which indicated that the effect of the factors on the responses was $96 \%$, while the rest were affected by error (Ross 2010). Hence, it can be concluded that the polynomial equation was reliable and can be used to predict the lipase productivity.

The experimental lipase productivity was similar to the predicted productivity. As shown in Figure 3, the distribution of the experimental points near to the trendline of the predicted productivity indicated that the experimental productivity can be accepted (Sridevi et al. 2011).

\subsubsection{Validity of the model and optimum lipase productivity}

The optimum lipase productivity was predicted using the response optimizer in RSM. The response optimizer is one of the RSM options in the Minitab software, which is used to analyze and predict the optimum responses. The output of the predicted result was shown as the optimum points solution of each factor and the value of the optimum response (Table 5). According to the validation result obtained, the value of experimental productivity was similar to that of the predicted productivity (Table 5), so the validation was fit and was successful.

According to Figure 4, the lipase productivity profile of A. niger KE1 showed that both media had a similar performance, such as low at the first incubation period (12-24 h), optimum at $72 \mathrm{~h}$, and subsequently decreasing until $168 \mathrm{~h}$ of incubation period. The increase of lipase productivity using the optimized medium was 4.7 -fold (373\%) after $72 \mathrm{~h}$ compared with the productivity using the initial medium. This result was higher than in previously reported studies (Jia et al. 2015; Ayinla et al. 2017; Wang et al. 2008).

The optimum medium only contained $2 \%$ peptone, $0.5 \%$ glucose, $0.075 \% \mathrm{MgSO}_{4} .7 \mathrm{H}_{2} \mathrm{O}$, and $0.1 \%$ olive oil. In this medium, peptone as the only nitrogen source is needed in higher concentrations to fulfil the needs of synthesis essential molecules, especially enzymes. Ghosh et al. (1996) reported a similar result, wherein the maximum lipase production of A. niger, Mucor racemosus, and Rhizopus nigricans was obtained in a medium containing $2 \%$ peptone.

The addition of olive oil in appropriate amounts can increase lipase production. However, in some microorganisms, higher olive oil concentration can inhibit lipase production. According to our results, our isolate can produce optimum lipase productivity in a medium containing a small amount of olive oil. Some research has reported that $0.1 \%$ olive oil resulting in maximum lipase production in Penicillium expansum, Penicillium citrinum, and Geobacillus thermodenitrificans (Stöcklein et al. 1993; Maliszewska and Mastalerz 1992; Balan et al. 2012).

TABLE 5. Validation of obtained polynomial equation (see Equation 1) from Box-Behnken design.

\begin{tabular}{cccccc}
\hline Peptone (\%) & Olive oil+glucose (\%) & $\mathrm{MgSO}_{4} .7 \mathrm{H}_{2} \mathrm{O}(\%)$ & \multicolumn{3}{c}{ Productivity (U/g biomass) } \\
\cline { 3 - 5 } & & & Predicted & Experimental \\
\hline 2 & $0.1: 0.5$ & 0.075 & 1595.98 & 1570.34 & $1377.8 ; 1814.2$ \\
\hline
\end{tabular}

Note: $\mathrm{Cl}=$ confidence interval, $\mathrm{PI}=$ predicted interval. 
The higher concentration of glucose than olive oil in the optimized medium may likely be due to the utilization of glucose by filamentous fungi to support their growth. Glucose, as a carbon source, is used to enhance hypha growth at the beginning of fermentation (Bindiya and Thiruveedula 2012). Furthermore, Jagtap et al. (2010) found that the increase in lipase production occurred when using the combination of glucose and $\mathrm{MgSO}_{4} \cdot 7 \mathrm{H}_{2} \mathrm{O}$, as carbon and mineral salt sources, respectively.

The optimized medium was considered more efficient with the reduction of some insignificant factors for lipase productivity. The optimized medium gave optimum lipase productivity though it only contained some components compared with the previous medium reported by Adham and Ahmed (2009). In addition, the utilization of a small amount of olive oil in the optimized medium can reduce the production cost, so it is useful to be applied in the industrial sector.

\section{CONCLUSION}

In this study, medium optimization of lipase productivity by A. niger KE1 was carried out by combining Taguchi and RSM designs. Lipase productivity was successfully increased with the reduction of medium components. Peptone, glucose, olive oil, and $\mathrm{MgSO}_{4} .7 \mathrm{H}_{2} \mathrm{O}$ were significant factors according to Taguchi analysis and these factors were optimized in RSM. The optimized medium was composed of $2 \%$ peptone, $0.5 \%$ glucose, $0.1 \%$ olive oil, and $0.075 \%$ $\mathrm{MgSO}_{4} .7 \mathrm{H}_{2} \mathrm{O}$. Using the optimal condition, lipase productivity was up to $1570.34 \mathrm{U} / \mathrm{g}$ biomass, 4.7 -fold higher than when using the initial medium. Meanwhile, the adequate polynomial equation predicted the lipase productivity successfully. Our results suggest that A. niger KE1 isolated from Kendari landfill soil is a potential lipase source that catalyses the esterification reaction. Further optimization research using various growth conditions is needed to obtain the optimal growth condition and maximize lipase production. The purification and characterization of the lipase enzyme from this isolate is also needed to determine the enzyme properties.

\section{Acknowledgements}

This study was partly supported by Universitas Gadjah Mada through the RTA program (nr. 3002/UN1/DITLIT/DIT-LIT/LT/2019). The authors are thankful to the Microbiology Laboratory of Universitas Halu Oleo for providing isolates in this research.

\section{AUTHORS' CONTRIBUTIONS}

NR obtained and analyzed the data, and wrote the manuscript. MI designed and supervised the study, analyzed the data, and wrote the manuscript.

\section{COMPETING INTERESTS}

The authors declare that they do not have any conflict of interest regarding this study.

\section{REFERENCES}

Adham NZ, Ahmed EM. 2009. Extracellular lipase of Aspergillus niger NRRL3; production, partial purification and properties. Indian J Microbiol. 49(1):77-83. doi: 10.1007/s12088-009-0004-2.
Akyıl MH, Cihangir N. 2018. Detection of lipase production from newly isolated Trichoderma citrinoviride. Hacettepe J Biol Chem. 2(46):229-235. doi:10.15671/hjb c.2018.231.

Awad GEA, Mostafa H, Danial EN, Abdelwahed NAM, Awad HM. 2015. Enhanced production of thermostable lipase from Bacillus cereus ASSCRC-P1 in waste frying oil based medium using statistical experimental design. J Appl Pharm Sci. 5(9):007-015. doi:10.7324/JAPS.2015. 50902.

Ayinla ZA, Ademakinwa AN, Agboola FK. 2017. Studies on the optimization of lipase production by Rhizopus sp. ZAC3 isolated from the contaminated soil of a palm oil processing shed. J Appl Biol Biotechnol. 5:30-37. doi: 10.7324/jabb.2017.50205.

Balan A, Ibrahim D, Abdul Rahim R, Ahmad Rashid FA. 2012. Purification and characterization of a thermostable lipase from Geobacillus thermodenitrificans IBRL-nra. Enzyme Res. 2012(2012):987523. doi:10.1155/2012/9 87523.

Bindiya P, Thiruveedula R. 2012. Optimization of lipase production from an indigenously isolated marine Aspergillus sydowii of Bay of Bengal. J Biochem Tech. 3:S203-S211.

Bora L, Bora M. 2012. Optimization of extracellular thermophilic highly alkaline lipase from thermophilic Bacillus sp isolated from hotspring of Arunachal Pradesh, India. Braz J Microbiol. 43(1):30-42. doi:10.1590/S1517-83 822012000100004.

Brooks AA, Asamudo NU. 2011. Lipase production by strains of Aspergillus species isolated from contaminated body creams. J Toxicol Environ Health Sci. 3(11):311-316. doi: 10.5897/JTEHS.9000049.

Chen HC, Ju HY, Wu TT, Liu YC, Lee CC, Chang C, Chung YL, Shieh CJ. 2011. Continuous production of lipasecatalyzed biodiesel in a packed-bed reactor: optimization and enzyme reuse study. J Biomed Biotechnol. 2011. doi:10.1155/2011/950725.

Cihangir N, Sarikaya E. 2004. Investigation of lipase production by a new isolate of Aspergillus sp. World J Microbiol Biotechnol. 20(2):193-197. doi:10.1023/B: WIBI.0000021781.61031.3a.

Costa MAF, Peralta RM. 1999. Production of lipase by soil fungi and partial characterization of lipase from a selected strain (Penicillium wortmanii). J Basic Microbiol. 39(1):11-15. doi:10.1002/(SICI)1521-4028(199903)39: 1<11::AID-JOBM11>3.0.CO;2-8.

Dutra JCV, da C Terzi S, Bevilaqua JV, Damaso MCT, Couri S, Langone MAP, Senna LF. 2008. Lipase production in solid-state fermentation monitoring biomass growth of Aspergillus niger using digital image processing. Appl Biochem Biotechnol. 147(1):63-75. doi:10.1007/s12010 -007-8068-0.

Facchini FDA, Vici AC, Pereira MG, Jorge JA, de Lourdes M, Polizeli T. 2015. Enhanced lipase production of Fusarium verticillioides by using response surface methodology and wastewater pretreatment application. J Biochem Technol. 6(3):996-1002. http://www.jbioch emtech.com/index.php/jbt/article/view/JBT637/p df.

Falony G, Coca Armas J, Dustet Mendoza JC, MartínezHernández J. 2006. Production of extracellular lipase from Aspergillus niger by solid-state fermentation. Food Technol Biotech. 44(2):235-240. https://hrcak.sr ce.hr/109860. 
Ghosh PK, Saxena RK, Gupta R, Yadav RP, Davidson S. 1996. Microbial lipases: production and applications. Sci Prog. 79(2):119-157. https://www.jstor.org/stable/434 21608.

Griffin DH. 1981. Fungal physiology. New York: John Wiley \& Sons.

Hasan F, Shah AA, Hameed A. 2009. Methods for detection and characterization of lipases: a comprehensive review. Biotechnol Adv. 27(6):782-798. doi:10.1016/j.bi otechadv.2009.06.001.

Hughes MN, Poole R. 1989. Metals and Microorganisms. London: Chapman \& Hall.

Iftikhar T, Niaz M, Ali E, Jabeen R, Abdullah R. 2012. Production process of extracellular lipases by Fusarium sp. using agricultural by products. Pak J Bot. 44:335-339. http://www.pakbs.org/pjbot/PDFs/44(SI1)/50.pdf.

Imandi SB, Karanam SK, Garapati HR. 2010. Optimization of media constituents for the production of lipase in solid state fermentation by Yarrowia lipolytica from palm Kernal cake (Elaeis guineensis). Adv Biosci Biotechnol. 1(2):115-121. doi:10.4236/abb.2010.12016.

Ire FS, Ike VC. 2014. Screening and optimization of process parameters for the production of lipase in submerged fermentation by Aspergillus carbonarius (bainer) IMI 366159. Annu Res Rev Biol. 4(16):2587-2602. doi:10.9 734/ARRB/2014/9879.

Jagtap S, Gore S, Yavankar S, Pardesi K, Chopade B. 2010. Optimization of medium for lipase production by Acinetobacter haemolyticus for healthy human skin. Ind J Exp Biol. 48:936-41. http://nopr.niscair.res.in/handle/1 23456789/10100.

Jia J, Yang X, Wu Z, Zhang Q, Lin Z, Guo H, Lin CSK, Wang J, Wang Y. 2015. Optimization of fermentation medium for extracellular lipase production from Aspergillus niger using response surface methodology. BioMed Res Int. 2015:e497462. doi:10.1155/2015/497 462.

Kwon DY, Rhee JS. 1986. A simple and rapid colorimetric method for determination of free fatty acids for lipase assay. J Am Oil Chem Soc. 63(1):89-92. doi:10.1007/BF 02676129.

Mahmoud G, Koutb M, Morsy F, Bagy M. 2015. Characterization of lipase enzyme produced by hydrocarbons utilizing fungus Aspergillus terreus. Eur J Biol Res. 5(3):70-77.

Mala JGS, Edwinoliver NG, Kamini NR, Puvanakrishnan R. 2007. Mixed substrate solid state fermentation for production and extraction of lipase from Aspergillus niger MTCC 2594. J Gen Appl Microbiol. 53(4):247-253. doi: 10.2323/jgam.53.247.

Malilas W, Kang SW, Kim SB, Yoo HY, Chulalaksananukul W, Kim SW. 2013. Lipase from Penicillium camembertii KCCM 11268: optimization of solid state fermentation and application to biodiesel production. Korean J Chem Eng. 30(2):405-412. doi:10.1007/s11814-012-0132-y.

Maliszewska I, Mastalerz P. 1992. Production and some properties of lipase from Penicillium citrinum. Enzyme Microb Technol. 14(3):190-193. doi:10.1016/0141-022 9(92)90064-U.

Mukhtar H, Haq I, Nawaz A, Rehman A, Hanif M. 2015. Studies on the lipase production by Aspergillus niger through solid state fermentation. Pak J Bot. 47:351-354. http://www.pakbs.org/pjbot/PDFs /47(SI)/48.pdf.
Nadia N, Nehad ZA, Elsayed AE, Essam MA, Hanan MA. 2010. Optimization of lipase synthesis by Mucor racemosus - production in a triple impeller bioreactor. Malays J Microbiol. 6(1):7-15.

Oliveira F, Souza CE, Peclat VROL, Salgado JM, Ribeiro BD, Coelho MAZ, Venâncio A, Belo I. 2017. Optimization of lipase production by Aspergillus ibericus from oil cakes and its application in esterification reactions. Food Bioprod Process. 102:268-277. doi:10.1016/j.fbp.2017.01.00 7.

Rodriguez JA, Mateos JC, Nungaray J, González V, Bhagnagar T, Roussos S, Cordova J, Baratti J. 2006. Improving lipase production by nutrient source modification using Rhizopus homothallicus cultured in solid state fermentation. Process Biochem. 41(11):2264-2269. doi:10.1016/j.procbio.2006.05.017.

Ross S. 2010. Introductory statistics. 3rd edition. Burlington: Academic Press.

Sharma AK, Sharma V, Saxena J. 2016. A review on optimization of growth parameters for enhanced fungal lipase production. Indo Am J Pharm Sci. 3(10):1196-1202. doi:10.5281/ZENODO.164935.

Sharma R, Chisti Y, Banerjee UC. 2001. Production, purification, characterization, and applications of lipases. Biotechnol Adv. 19(8):627-662. doi:10.1016/s0734-9750 (01)00086-6.

Sridevi V, Veera C, Mahanti V, Venkata S, Adimadhyam N, Medicherla N. 2011. Statistical optimization of process variables by response surface methodology to enhance phenol degradation by Pseudomonas putida (NCIM 2102). Adv Biosci Biotechnol. 02(04):175-181. doi: 10.4236/abb.2011.24028.

Stöcklein W, Sztajer H, Menge U, Schmid RD. 1993. Purification and properties of a lipase from Penicillium expansum. Biochim Biophys Acta Lipids Lipid Metab. 1168(2):181-189. doi:10.1016/0005-2760(93)90123-Q.

Subramonian S, Milkey K, Samsudin A, Dubey A, Kidd P. 2014. Comparison between taguchi method and response surface methodology (RSM) in modelling $\mathrm{CO}_{2}$ laser machining. Jordan J Mech Ind Eng. 8(1):35-42.

Teng Y, Xu Y. 2008. Culture condition improvement for whole cell lipase production in submerged fermentation by Rhizopus chinensis using statistical method. Bioresour Technol. 99(9):3900-3907. doi:10.1016/j.bi ortech.2007.07.057.

Thakur S. 2012. Lipases, its sources, properties and applications: a review. Int J Sci Eng Res. 3(7):1-29.

Wang D, Xu Y, Shan T. 2008. Effects of oils and oil-related substrates on the synthetic activity of membranebound lipase from Rhizopus chinensis and optimization of the lipase fermentation media. Biochem Eng J. 41(1):30-37. doi:10.1016/j.bej.2008.03.003.

Xia Jl, Huang B, Nie Zy, Wang W. 2011. Production and characterization of alkaline extracellular lipase from newly isolated strain Aspergillus awamori HB-03. J Cent South Univ. 18(5):1425-1433. doi:10.1007/s11771 -011-0857-5.

Yanti NA, Sriwahyuni E, Rayani N, Muhiddin NH, Ahmad SW. 2019. The potential of lipolytic filamentous ftungi isolated from landfill soil as poly- $\beta$-hydroxybutirate (PHB) bioplastic degrader. BioRxiv. doi:10.1101/2019.12.19.883 538. 